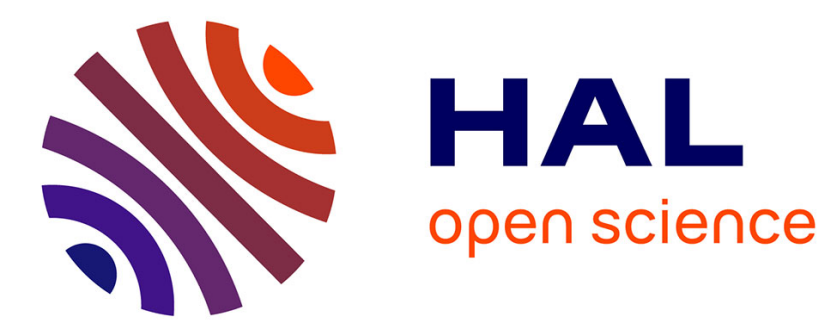

\title{
Selecting one out of six stereoisomers
}

Damien Bonne, Jean Rodriguez

\section{To cite this version:}

Damien Bonne, Jean Rodriguez. Selecting one out of six stereoisomers. Nature Catalysis, 2021, 4 (6), pp.451-452. 10.1038/s41929-021-00639-5 . hal-03278289

\section{HAL Id: hal-03278289 \\ https://hal.science/hal-03278289}

Submitted on 5 Jul 2021

HAL is a multi-disciplinary open access archive for the deposit and dissemination of scientific research documents, whether they are published or not. The documents may come from teaching and research institutions in France or abroad, or from public or private research centers.
L'archive ouverte pluridisciplinaire HAL, est destinée au dépôt et à la diffusion de documents scientifiques de niveau recherche, publiés ou non, émanant des établissements d'enseignement et de recherche français ou étrangers, des laboratoires publics ou privés. 


\section{Selecting one out of six stereoisomers}

The design of an original molecular architecture featuring an unusual sterically congested $C\left(s p^{2}\right)-C\left(s p^{3}\right)$ stereogenic axis with six high rotational barriers results in the formation of six stereoisomers. The configuration of this axis can be controlled by transition metal catalysis and one stereoisomer can be produced selectively.

\section{Damien Bonne and Jean Rodriguez}

n 1874, Le Bel ${ }^{1}$ and van 't Hoff ${ }^{2}$ independently found that the four valencies of the carbon atom are directed towards the vertices of an atom-centred tetrahedron. This discovery laid the foundations of the theory of molecular structure. The now-very-popular Le BelVan 't Hoff rule of stereochemistry is taught to undergraduate students. This rule states that the total number of stereoisomers of a molecule with no internal plane of symmetry is $2^{n}$, where $n$ represents the number of stereogenic elements ${ }^{3}$. Therefore, molecules containing one stereogenic element - such as a stereocentre or a less-encountered axis, plane or helix - can exist as two stereoisomers which are, in this case, enantiomers of opposite configuration.

Controlling the configuration of one stereogenic element at a time is a well-mastered task ${ }^{4,5}$, thanks to the development of enantioselective catalysis interactions between a chiral catalyst and the substrates produce two diastereomeric transition states, with the less energetic one being favoured over the other one. This leads to the formation of one major enantiomer.

Now, writing in Nature Catalysis, Christof Sparr and co-workers have developed an enantioselective rhodium-catalysed $[2+2+2]$-cyclotrimerization leading to the formation of one out of six stereoisomers with up to 0:0:2:98:0:0 stereocontrol ${ }^{6}$. This was made possible thanks to the design of chiral 9-aryltriptycene derivatives featuring an unusual $\mathrm{C}\left(s p^{2}\right)-\mathrm{C}\left(s p^{3}\right)$ stereogenic axis that offers six high rotational barriers. Pioneering observations of slowed rotation around a $\mathrm{C}\left(s p^{2}\right)-\mathrm{C}\left(s p^{3}\right)$ stereogenic axis were observed by Nakamura and Ōki in 1975 using dynamic nuclear magnetic resonance ${ }^{7}$ and were also found to be present in some interesting families of natural products ${ }^{8}$. In the work reported in Nature Catalysis, the designed, intriguing axially chiral molecule exists as several isolable configurations resulting from the sterically congested $\mathrm{C}\left(s p^{2}\right)-\mathrm{C}\left(s p^{3}\right)$ stereogenic axis triggering unusually high rotational barriers to go from one stereoisomer to another.

The researchers started their work with feasibility studies in the racemic series from a substrate lacking the ketone function (highlighted in pink in Fig. 1). In this case, the expected formation of the six stereoisomers as a mixture of three couples of racemic diastereomers was observed and they were identified as synperiplanar $(s p)$, clinal (c) and antiperiplanar ( $a p)$ with respect to the relative position between the ketone function and the $\mathrm{N}-\mathrm{R}^{2}$ group in a diastereomeric ratio of $1: 1.3: 1.5$, respectively. All six stereoisomers could be resolved by high-performance liquid chromatography (HPLC) on a chiral stationary phase. Slow interconversion between some of them indicated that some of the rotational barriers were not high enough to prevent the rotation. Interestingly, the enantiomerization of the antiperiplanar $(a p)$ isomers, which required the bulky adamantyl group (Ad) to go through the inner imide's carbonyl group, was not observed. This suggests that the rotational barrier was high enough to prevent rotation in this case.

With the ketone functional group (highlighted in pink in Fig. 1), all rotational barriers increased above $110 \mathrm{~kJ} \mathrm{~mol}^{-1}$, preventing interconversion between the stereoisomers at room temperature. This substrate was chosen for the optimization of the enantioselective catalyst-controlled $[2+2+2]$-cyclotrimerization reaction. Several chiral ligands were used, which allowed identification of the bisphosphine $\left(S_{\mathrm{a}}\right)$-xyl-SDP as the best one and gave the desired product in good yield (75\%) and with excellent stereoselectivity. Only antiperiplanar $(a p)$ pair of enantiomers was formed, with high enantioselectivity for the (+)-ap enantiomer (0:0:7:93:0:0).

The scope was then investigated and the authors found an important effect of the $\mathrm{R}^{2}$ group on the enantioselectivity, which was superior for electron-poor aryl groups. The
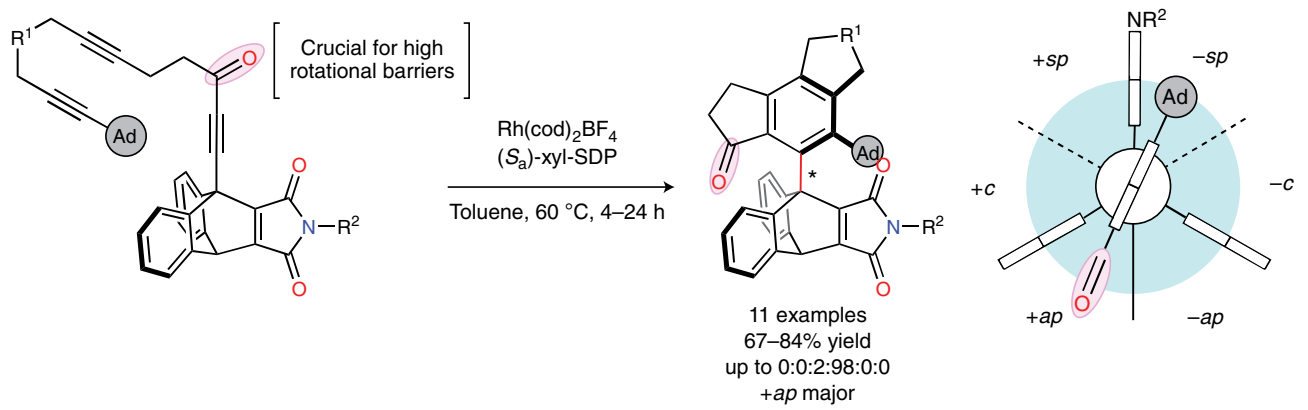

$\left(S_{\mathrm{a}}\right)$-xyl-SDP

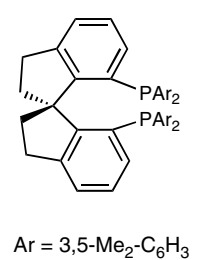

Fig. 1 | Catalyst control over higher-order stereogenicity. The use of a chiral rhodium complex as catalyst in a $[2+2+2]$-cyclotrimerization reaction allows the formation of one major cycloadduct among the six possible stereoisomers. 
influence of the nature of the tether moiety between both triple bonds ( $\mathrm{R}^{1}$ group, Fig. 1) showed that both a $\mathrm{N}$-tosyl group and a diethyl malonate linkage were compatible and gave good yields and stereoselectivities. An additional stereogenic $\mathrm{C}-\mathrm{N}$ bond could be installed in the product when $\mathrm{R}^{2}$ was a bulky ortho-ethoxyphenyl group, leading to a 2:1 mixture of rapidly interconverting $\mathrm{C}-\mathrm{N}$ atropisomers, due to a low rotational barrier of this stereogenic bond $\left(70 \mathrm{~kJ} \mathrm{~mol}^{-1}\right)$.

Finally, the stereodivergent nature of this transformation was demonstrated ${ }^{9}$ : the use of a chiral $\mathrm{N}$-heterocyclic carbene (NHC) ligand led to selective formation of clinal $(c)$ isomers over the antiperiplanar $(a p)$ isomers (d.r. $=83: 17)$, with high enantioselectivity (e.r. = 94:6). Here also, formation of the synperiplanar $(s p)$ isomers was not observed. Hence, by careful selection of either a chiral bisphosphine or an NHC ligand, four of the six stereoisomers are accessible, each of them with good enantioselectivity.

The methodology developed by Sparr's group represents a striking realization in catalyst-controlled reactions achieving control over higher-order stereogenicity.
They have showed that the ingenious design of a molecule and its stereogenic element, a rare sterically congested $C\left(s p^{2}\right)-C\left(s p^{3}\right)$ bond, can lead to the existence of more than two stereoisomers, six in this case. This is possible because the resulting multiple conformations become multiple configurations due to the different high rotational barriers. In addition, stereodivergent synthesis of four of the six stereoisomers was accomplished by switching the catalyst. Probably for steric reasons, only the synperiplanar $(s p)$ isomers could not be obtained selectively. This challenge could be solved using catalyst design, which would undeniably constitute a major achievement for stereodivergent transformations.

We do believe that this emerging area of research is opening unforeseen possibilities and will have a deep impact on future developments in stereoselective catalysis. This work represents an important milestone in both atropisomerism and stereoselective catalysis, and should trigger new ideas and realizations in many research groups.
Damien Bonne (1) $₫$ and Jean Rodriguez ${ }^{凶}$ Aix-Marseille Université, CNRS, Centrale Marseille, iSm2, Marseille, France.

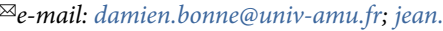

rodriguez@univ-amu.fr

1. Le Bel, J. A. Bull. Soc. Chim. Fr. 22, 337-347 (1874).

2. van 't Hoff, J. H. Archs. Neerland. Sci. Exactes et Naturelles 9 , 445-454 (1874).

3. Grossman, R. B. J. Chem. Educ. 66, 30-33 (1989).

4. Blaser, H. U. \& Federsel, H.-J. (eds) In Asymmetric Catalysis on Industrial scale: Challenges, Approaches and Solutions 2 nd edn (Wiley-VCH, 2010).

5. Cheng, J. K., Xiang, S.-H., Li, S., Ye, L. \& Tan, B. Chem. Rev. 121, 4805-4902 (2021)

6. Wu, X. et al. Nat. Catal. https://doi.org/10.1038/s41929-02100615-z (2021).

7. Nakamura, M. \& Ōki, M. Bull. Chem. Soc. Jpn. 48 2106-2111 (1975).

8. He, Q.-F. et al. J. Org. Chem. 86, 5870-5882 (2021)

9. Krautwald, S. \& Carreira, E. M. J. Am. Chem. Soc. 139, 5627-5639 (2017). 